\title{
Toward a Paradigm Shift in Urban Planning in Tehran: Neighborhood Development Plans
}

\author{
Kaveh Hajialiakbari ${ }^{1, *}$, Mitra Karimi ${ }^{2}$, Safiye Tayebi ${ }^{3}$ \\ ${ }^{1}$ Faculty of Architecture and Urban Planning, Shahid Beheshti University, Tehran, Iran \\ ${ }^{2}$ Faculty of Fine Arts, University of Tehran, Tehran, Iran \\ ${ }^{3}$ Faculty of Geography, University of Tehran, Tehran, Iran
}

Received January 5, 2021; Revised May 23, 2021; Accepted October 15, 2021

\section{Cite This Paper in the following Citation Styles}

(a): [1] Kaveh Hajialiakbari, Mitra Karimi, Safiye Tayebi , "Toward a Paradigm Shift in Urban Planning in Tehran: Neighbourhood Development Plans," Civil Engineering and Architecture, Vol. 9, No. 7, pp. 2492 - 2504, 2021. DOI: 10.13189/cea.2021.090733.

(b): Kaveh Hajialiakbari, Mitra Karimi, Safiye Tayebi (2021). Toward a Paradigm Shift in Urban Planning in Tehran: Neighbourhood Development Plans. Civil Engineering and Architecture, 9(7), 2492 - 2504. DOI: 10.13189/cea.2021.090733.

Copyright $\odot 2021$ by authors, all rights reserved. Authors agree that this article remains permanently open access under the terms of the Creative Commons Attribution License 4.0 International License

\begin{abstract}
Establishment of facilitation offices in deteriorated neighborhoods of Tehran for more than a decade has led to a significant transition from top-down and authoritative intervention into a bottom-up and participatory-based renewal; one of the important parts of this transition is the adoption of a distinct approach to provide neighborhood development plans (NDPs). This approach is based on the identification of the main problems of neighborhoods, attention to all dimensions, adaptation with parallel and upstream plans, and activation of the participation of local communities and collaboration of stakeholders in public, private, and third sectors. In this paper, the neighborhood development planning approach to the problem of deterioration and obsolescence in Tehran is defined; the most important parts are the content, features, process of provision, executive framework, and assessment phases of the plan. Despite the necessity of urban renewal-regeneration integrated and systematic planning, the challenge of ignoring the unique characteristics of neighborhoods will be addressed by NDPs Scaling and Framing. Actually by defining a new level in medium and short-term plans, Tehran Municipality changed the approach of urban planning. Developing a dynamic, flexible, partnership-driven and scalable framework for dealing with the urban decay to correctly identify the neighborhoods key issues and the point solutions has been the new approach's main objective.
\end{abstract}

Keywords Neighborhood Development, Deteriorated Neighborhoods, Neighborhood Development Offices, Participation, Community

\section{Introduction}

Cities are changing dynamically and the speed and scale of urbanisation brings tremendous challenges [1]. In the process of transition, cities are facing new problems, so urban governance and planning must be flexible and improvable at all scales. The subject of urban management, which had been discussed in UN-Habitat declarations, emphasises urban good governance to tackle mentioned challenges; Taylor defines Good governance as an enabling tool that empowers cities to carry out their functions with the maximum effectiveness to improve the quality of life in cities, especially for underprivileged and marginalized groups [2]. Due to the uncertainty, diversity, and instability of drivers of the performance of cities [3], an efficient and effective planning model must utilise the most flexible approach to face the unforeseen crises readily. Such model encompasses economic, social, physical, and cultural infrastructures [4]. On the other hand, the criteria of good governance, is researched by Biswas and others, which proves the important place of participatory planning models that ensure inclusive urban plans [5]. Also, Cruz, 
by reviewing current themes and future priorities, focuses on Top 20 urban governance challenges and ranks the "Citizen participation" as the most important and frequent challenge of urban governance [6]. Hence, by concentrating on the concept of inclusive city and inclusive decision-making as the heart of urban good governance [2], in a city, it begins from the smallest programmable level (neighbourhood). Due to the effective cooperation of stakeholders and the focus on common goals, neighbourhood planning is likely to lead to successful urban design [7]. Planning at the neighbourhood scale is recognised essential for achieving sustainable development. For over a century, planners and visionaries have developed planned neighbourhoods as remedies for problems that have been caused by unregulated urbanisation [8].

Urban deterioration is one of the consequences of rapid urbanisation and one of the most important urban problems that has been faced in both more and less developed countries in different ways [9]. Urban decay can be traced by following the patterns of urban development and loss of local identities in the process of globalisation in the economic and functional roots of the city [10].

In Iran, since two decades ago, the problem of neighbourhood deterioration has been addressed on the public sector agenda in national and municipal levels with the approval of numerous regulations and the creation of various institutions. Neighbourhood deterioration has diverse causes such as human behaviour (priorities and options of human agent, social solidarity, sense of place, and seeking of opportunities), physical manifestations (instable buildings and brownfields), and the role of institutions and organisations (ineffective urban management and inefficient allocation processes) [11]; in fact, a combination of aforementioned factors can be led to the neighbourhood deterioration. Accordingly, in different eras, various approaches and policies have been taken as intervention framework by urban management and put different outcomes and consequences.

The need for a self-regenerating socio-ecological system (to ensure sustainability) is gaining great attention as an essential concept for transformative processes [12]; when facilitating sustainable development at the local level, neighbourhood planning is arguably important [13]. This is a reason for determining a real role for citizen's partnership in regeneration plans [14] because achieving these ideals is not possible except by returning to the smallest level of society, i.e. neighbourhoods (local communities) and retaking the wills and opinions of the citizens into consideration through participatory planning and decision-making. The successful process of citizen-cantered planning and local development will make people aware of the benefits and potentials of this process and encourage them to allocate more finance and time in it; also this will be the beginning of a participatory budgeting process [15]. Also, conflicts between the interests of different groups have made the fulfilment of the principles of local democracy and justice inevitable; especially in metropolitan areas where the interests of individuals with different ethnic, class, worldview, gender, and other origins encounter. Hence, Community development is the capacity for people to work collectively in addressing common interests [16].

The models that involve all actors in the planning and implementing processes have multidimensional and complex structures. Practice and realisation of these models needs the multifaceted participation of the local communities and institutions. Only if the local community get involved in the planning process, they will support it [17]. Hence, generating inclusive and direct participation is a process that takes people's needs and values into account in collective decision-making; this process establishes mutual communication and interaction for making better and more achievable decisions [18]. Therefore, neighbourhood planning and development is an interactive approach for urban management at local level; this approach needs specific framework for different agendas, issues, and contexts.

In Iran, despite the passing of 6 decades since the establishment of urban planning mechanism, this mechanism has not been able to achieve planning goals due to the elitism tendency and lack of interaction with all stakeholders; hence, it can be concluded that urban deterioration and establishment of informal settlements are the consequences of the failure of the urban planning system.

In Tehran, 196 neighbourhoods have at least one deteriorated block ${ }^{1}$, while $65 \%$ of the deteriorated blocks are concentrated in 56 neighbourhoods in the central and southern parts of the city (Figure 1); this means the spatial concentration of deteriorated neighbourhoods in the inner parts of the capital [19].

Deteriorated neighbourhoods do not be enhanced automatically and spontaneously and cannot be developed like other parts of the city; but their multidimensional problems need an integrated intervention-based approach by considering physical, functional, social, economic, environmental, legal, and managerial aspects. As a result, a planning framework to address the key problems of deteriorated neighbourhoods and navigate them to sustainability is needed; in this paper, this framework (Neighbourhood Development Plan-NDP) is explained.

1 Deteriorated block is defined based on the indices of Supreme Council of Urban Planning and Architecture of Iran and is a block that its majority of parcels have instable buildings, are impermeable (are accessed from paths with width less than $6 \mathrm{~m}$ ), and have area less than $200 \mathrm{~m}^{2}$ [30]. 


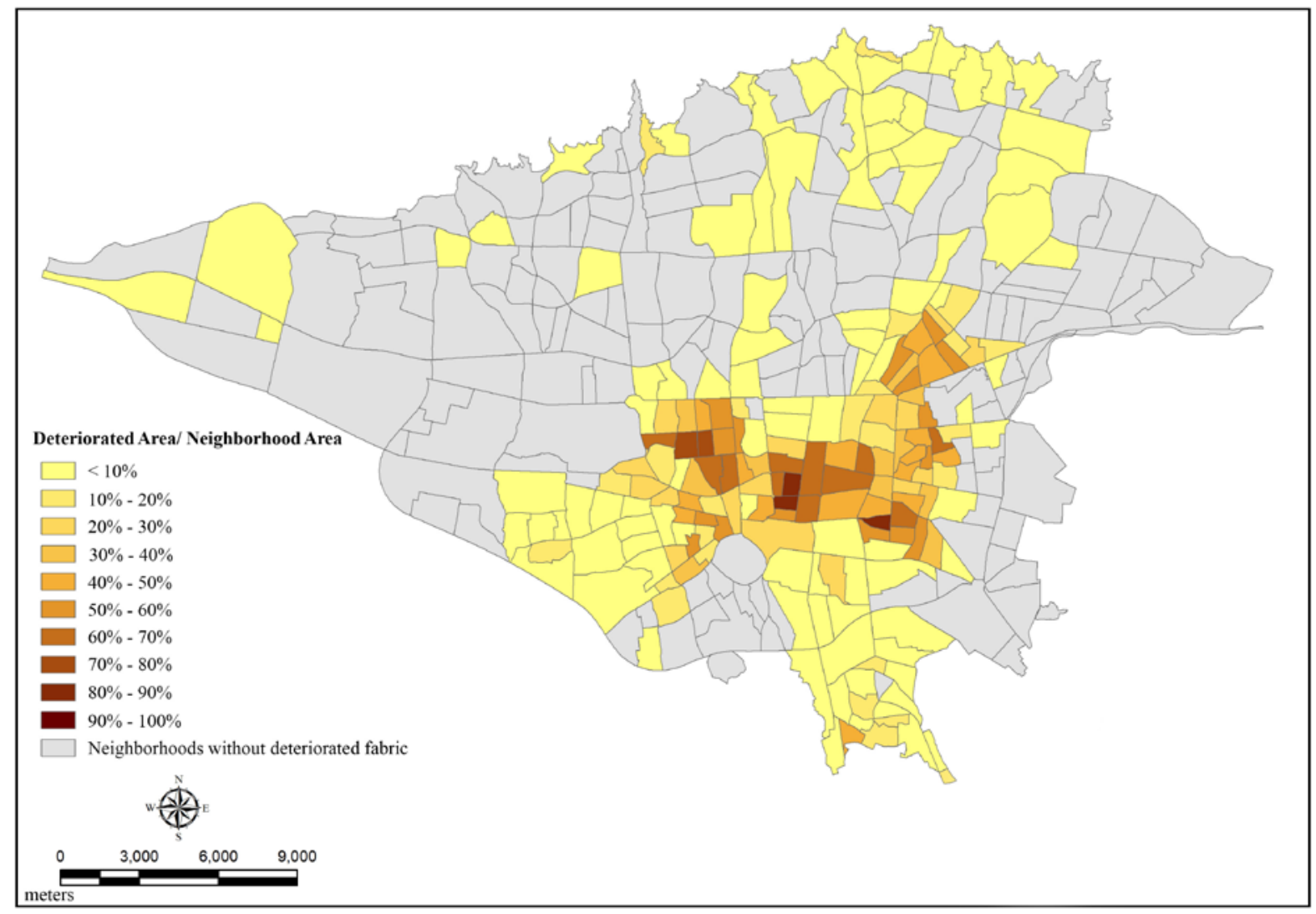

Source: [20]

Figure 1. Spatial concentration of deteriorated neighborhoods in Tehran

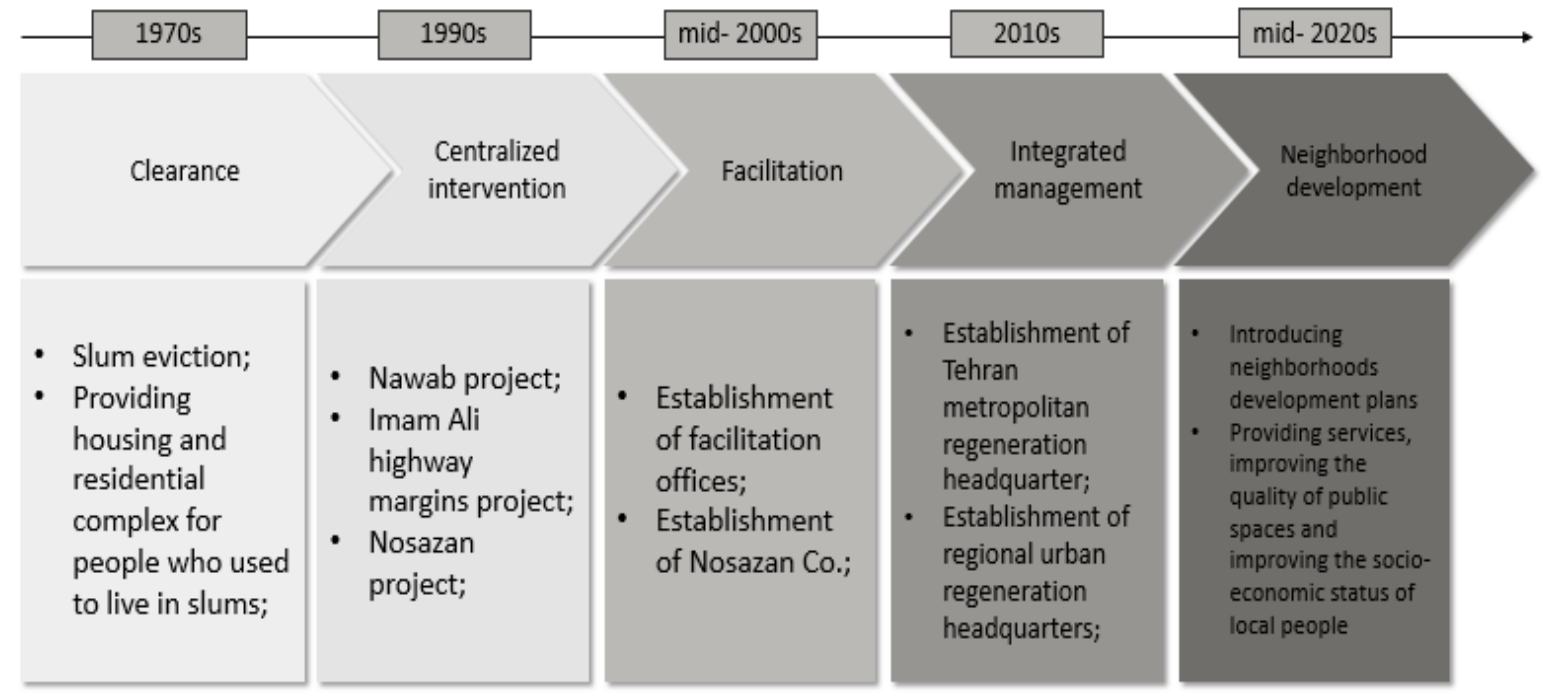

Figure 2. trajectory of intervention in deteriorated neighbourhoods in Tehran, Source: (Developed by Authors). 


\section{Materials and Methods}

This paper has been prepared based on the experience of $\mathrm{UROT}^{2}$ in planning for deteriorated neighbourhoods in last decade. Definition of NDP in this paper is based on the analysis and assessment of previous and current policies, plans, and institutions; so, the materials that have been studied in this paper include:

- analysis of the procedure and substance of 4 planning frameworks that have been adopted for deteriorated neighborhoods of Tehran in recent 15 years (based on 3 categories and 18 indicators (table 1));

- assessment of the official policies, regulations, and institutions and the possible position of NDP in them;

By evaluating these materials (based on content analysis), a definition of NDP has been developed and its features, content, and process has been explained.

\subsection{Analysis of Status Quo}

In Tehran, in dealing with deteriorated neighbourhoods, distinct intervention approaches have been examined since 1970s. After experience of slum clearance in 70s and 80s, an authoritative and top-down intervention was started in 90s by "Navvab-Safavid" and similar project[21]. However, since mid-2000s, due to the failure of this approach, UROT has adopted a facilitative, integrative, and neighbourhood-based intervention approach (figure 2) [22].

The main incentive of this paradigm shift was the establishment of "neighbourhood development offices (NDOs)" in deteriorated neighbourhoods which led to a tangible transition from authoritative, mega-scale, and top-down intervention to planning and implementation based on dialogue, consultation, and partnership with the local communities (Hajialiakbari,2015).
Regarding urban development plans until 2018, four plans had been provided for deteriorated neighbourhoods of Tehran; the comprehensive plan of the city (and the detailed plans of districts based on it); the townscape plans of deteriorated neighbourhoods ${ }^{3}$ [23]; the neighbourhood renewal plans (were provided by UROT's facilitation offices ${ }^{4}$ ); and the TU's ${ }^{5} 2^{\text {nd }}$ development plan $^{6}$ Comprehensive (and detailed) plan focuses on the organization of land-use, population, and accessibility in the city; townscape and Renewal plans address the intervention issues directly at the neighborhood level; and the development plan of TM determines the course of actions of different sectors of the municipality. In this research, to analyze the status quo and understand the necessary factors to be contained, mentioned plans have been assessed based on 18 criteria (Table 1).

Evaluation of the content of table 1 shows that emphasis on physical aspect and neglecting the other dimensions (and their effects on the neighbourhood deterioration) is the common weak spot of comprehensive, townscape, and TU's development plans; regarding neighbourhood renewal plans, despite paying attention to non-physical factors, the uniqueness of context, and the main problems of neighbourhood, ambiguity on the stakeholders' participation in planning process and lack of interaction with other planning levels have turned these plans into non-executive instruments. In all plans, a shortage of participation-encouraging mechanisms, focusing just on the capabilities of the municipality in the implementation process and lack of coordination with other public bodies are common weaknesses. Hence, a need for neighbourhood-based, interactive, and participatory plan is clear.
2 Urban Renewal Organization of Tehran (UROT) was established in 1968 and is the responsible agency for urban renewal and regeneration in Tehran Municipality.
3 A type of land use plan and urban design for deteriorated neighborhoods which was provided by UROT between 2005 and 2010 for more than 70 neighborhoods.

4 In neighborhood renewal process in Tehran, facilitation is defined as the acceleration of the success of a group, the creation of interaction in the community, and provision of necessary structures to attain best outcomes through participation. In this context, the necessity for facilitation arises from the deprivation of local communities and the need for a mediator to begin and smooth the process of participation. Based on this definition, a variety of experts on social sciences, urban planning and design, architecture, law, and economic sciences organize the structure of the facilitation office. Since 2010, establishment of facilitation offices has been the main policy of UROT to accelerate neighborhood renewal. For more information, look at: [29].

5 Tehran Municipality

6 In Tehran, the main duties and responsibilities of the municipality is determined in a 5-years plan and is approved by the city council. 
Table 1. Development plans of Tehran in a comparative model, Source: (Developed by Authors)

\begin{tabular}{|c|c|c|c|c|c|c|c|c|c|c|c|c|c|c|c|c|c|c|}
\hline & \multicolumn{6}{|c|}{ content } & \multicolumn{6}{|c|}{ Planning process } & \multicolumn{6}{|c|}{ Implementation process } \\
\hline criteria & 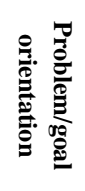 & 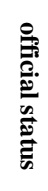 & 焉 & 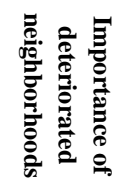 & $\hat{s}_{0}^{0}$ & 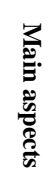 & 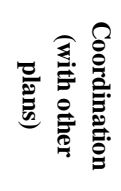 & 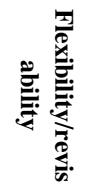 & 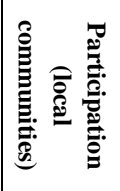 & 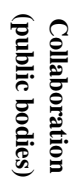 & 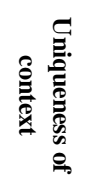 & 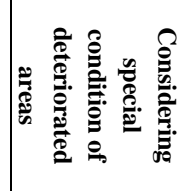 & 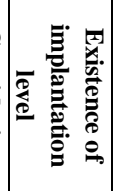 & 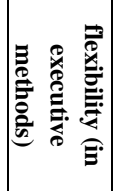 & 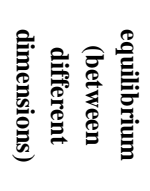 & 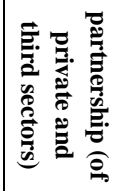 & 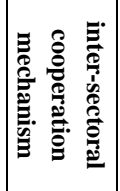 & 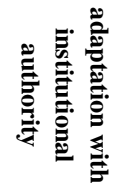 \\
\hline $\begin{array}{c}\text { Comprehensive } \\
\text { (and detailed) plan } \\
\text { (2006) } \\
\text { lack of a distinct } \\
\text { policy for } \\
\text { intervention in } \\
\text { deteriorated } \\
\text { neighborhoods } \\
\text { lack of participation } \\
\text { and interaction in } \\
\text { planning process; } \\
\text { focus on the } \\
\text { physical aspect and } \\
\text { neglecting the social } \\
\text { and economic } \\
\text { dimensions; } \\
\text { ignore of specific } \\
\text { features of } \\
\text { neighborhoods; }\end{array}$ & 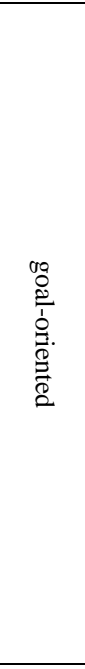 & + & 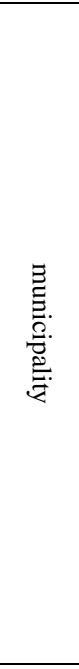 & 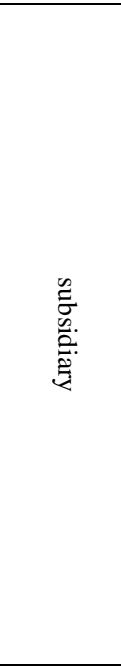 & 尺े & 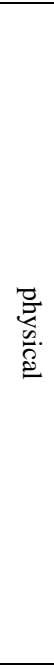 & + & 营 & & ' & 1 & 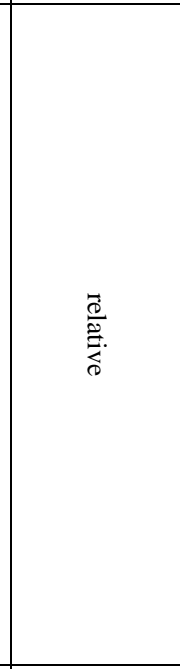 & ' & ' & ' & ' & ' & 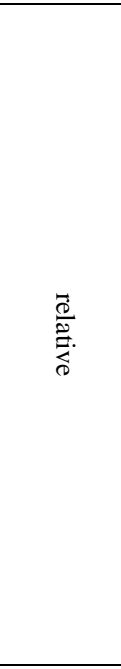 \\
\hline $\begin{array}{c}\text { Townscape plan } \\
\text { (2005-10) } \\
\text { paying special } \\
\text { attention to physical } \\
\text { aspect; } \\
\text { lack of } \\
\text { context-based } \\
\text { approach; } \\
\text { lack of } \\
\text { implementation } \\
\text { mechanism; } \\
\text { lack of flexibility; }\end{array}$ & 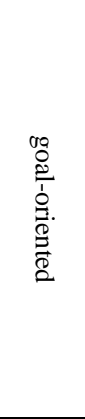 & + & 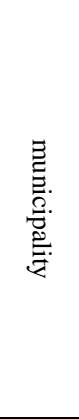 & 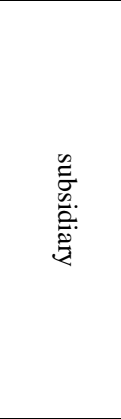 & $\stackrel{?}{\nexists}$ & $\begin{array}{l}\text { D. } \\
\overline{2} \\
0 . \\
0.2\end{array}$ & + & 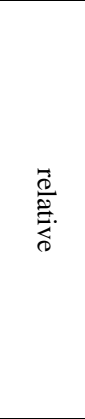 & ' & ' & ' & 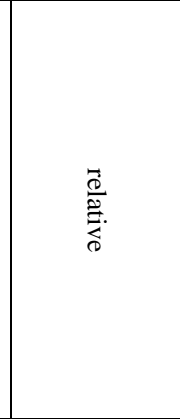 & + & ' & ' & ' & ' & 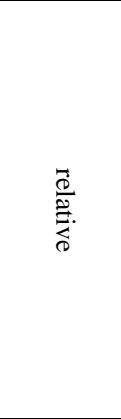 \\
\hline
\end{tabular}




\section{Table 1 Continued}

\begin{tabular}{|c|c|c|c|c|c|c|c|c|c|c|c|c|c|c|c|c|c|}
\hline $\begin{array}{c}\text { Renewal plan } \\
\text { (2010-18) } \\
\text { lack of official } \\
\text { position; } \\
\text { Lack of } \\
\text { implementation } \\
\text { mechanism; } \\
\text { lack of institutional } \\
\text { participation; } \\
\end{array}$ & 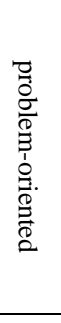 & ' & 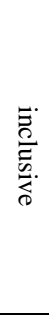 & 葾. & 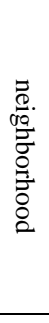 & 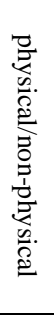 & ' & + & 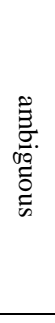 & ' & + & 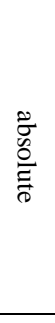 & + & + & ' & + & ' \\
\hline $\begin{array}{l}\text { TU's development } \\
\text { plan } \\
\text { pay the least } \\
\text { attention to people's } \\
\text { opinions and their } \\
\text { participatory role; } \\
\text { lack of a mechanism } \\
\text { for cross-sectoral } \\
\text { cooperation (within } \\
\text { the municipality and } \\
\text { other institutions); }\end{array}$ & $\begin{array}{l}\frac{0}{0} \\
0 \\
0 \\
0 \\
0 \\
0 \\
0 \\
0 \\
0 \\
0 \\
0 \\
0\end{array}$ & + & 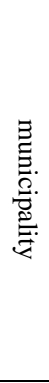 & 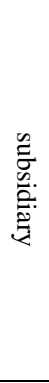 & $\stackrel{\nexists}{~}$ & 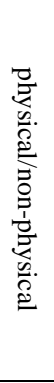 & + & + & ' & + & ' & 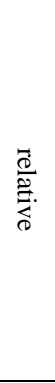 & + & 1 & ' & + & ' \\
\hline
\end{tabular}




\subsection{Determining the Official Position of NDP}

One of the prerequisites that can guarantee the realisation of NDP is its distinct and legal position in urban planning hierarchy; the definition of this position can determine NDP's accordance (as a micro plan) with the meso and macro plans (such as TU's periodical plan and the comprehensive plan of the city) on one hand, and its contextual adaptation with the unique characteristic of each neighbourhood on the other hand. This kind of adaptation can build consensus diverse agencies and stakeholders about goals, strategies, policies, and actions of the plan.

Determination of appropriate place of NDP cannot be imagined without considering current laws and regulations, capacities of effective institutions, and capabilities of public bodies. In Iran, with the approval of the "Sixth Development Plan" of the country in 2016, concentration on neighbourhood scale in intervention and the necessity of budget allocation in this scale was formalised [24]; also, in 2014, the "National Strategic Plan of Urban Regeneration" was approved by the state and a "National Urban Regeneration Council (NURC)" was established by the attendance of 30 relevant agencies in public sector [25]; in these regulations, the neighbourhood scale for provision of regeneration plans in deteriorated neighbourhoods was admitted and NURC was assigned to provide a collaborative framework for the implementation of these plans; the NURC has a municipal level in Tehran (Urban Regeneration Council of Tehran) which has the authority to check and approve NDPs [26]. Accordingly, in the third five-year development plan of Tehran, which was approved in 2018 by the city council, the need for NDP for all neighbourhoods (especially for deteriorated and less-developed neighbourhoods) and definition of TU's actions based on it was formalised [27].

Based on aforementioned policies, UROT started to prepare NDPs for 170 deteriorated neighbourhoods in 2018 and TU was obligated to determine the share of these plans in annual programs and budgets. The programmes, projects, and actions that are the outcome of NDPs are proposed in three levels (long/mid/short-term) [20] and are approved by the "Urban Regeneration Council of Tehran".

\subsection{Definition of NDP}

Lai considers the urban development process as a set of five partially independent streams of problems, solutions, decision-makers, locations, and decision situations; when the elements of the five streams collide under some structural constraints and fulfil an energy surplus decision rule, decisions are made [28]. Such model embedded on the process of planning and the planners which play an intersectional role in the neighbourhood.

In Tehran, dealing with deteriorated neighbourhoods, a NDP is described as a plan that prepares a framework for dealing with the key problems (existing in the present or can be appeared in future) that the neighbourhood faces; this plan, with a proactive approach, identifies problems and solutions with the participation of local community and collaboration of relevant stakeholders. The main intention is to navigate neighbourhood to a more-developed vision.

The NDP covers all the problems and weaknesses that are related to the previous plans in terms of content, preparation, and implementation process. So, the plan has a flexible framework and cyclic process and its content depends on the specific and unique circumstances of neighbourhood. Also, NDP involves all stakeholders of the development in planning process, and provides the possibility of collaboration of all effective bodies in the public, private, and third sectors. Hence, the most important goals of preparing a NDP are:

- To identify and analyze causal mechanisms of deterioration and focus on underdevelopment problems in various aspects;

- To resolve existing obstacles of development and prevent the formation of new problems in the future;

- To highlight the position of deteriorated neighborhoods in urban development plans in the allocation of public sector resources;

- To activate the local communities' participation and institutional cooperation.

Based on the definition and the goals of preparing NDP in the deteriorated neighbourhoods of Tehran, its main features can be explained as below:

- integration: balanced attention to all dimensions that effect the deterioration of neighborhood;

- Holism: considering the interaction of neighborhood with other spatial levels and inter-relation of the plan with other spatial plans and programs;

- Problem-orientation: concentration on the most important problems by identification and analyze of the main problems and imagination of casual relation between diverse problems;

- Contextualism: considering the uniqueness of context and attention to the distinct problems, needs, demands, and capacities of each neighborhood and every local community;

- inclusiveness: activate the participation and collaboration of the majority of stakeholders and partners in problem-definition, planning, implementation, monitoring, and revise stages;

- Feasibility: adaptation of plan with the legal, technical, financial, and executive authority of stakeholders;

- Flexibility: definition of a cyclic manner to planning process and the need to continual and periodical redefinition of plan's agenda, goals, strategies, policies, projects, and action.

The content of NDP has two substantial and procedural aspects; while physical, environmental, social, and economic dimensions define its substantial structure, the good governance system can be assigned as procedural dimension. Each dimension has its criteria, indices, and measures; about 70 measures define the content of NDP 
and is measured and monitored annually by NDOs.

\section{Discussion}

The process of preparing and implementing a NDP is completely participatory and involves all stakeholders at local communities and related institutions. In all stages of this process, the content of the plan is emphasised and each issues are solved in a specific planning and budgeting subprocess (Figure 3).

\subsection{The Process of Preparing a NDP}

An appropriate process to provide a NDP should be defined based on the analysis and pathology of status quo and considering the main weak spots of past plans. The following steps are the key considerations of the process of NDP.

\subsubsection{The Planner}

The first precondition to provide a NDP is to opt for an appropriate planner; since the planning, implementation and monitoring processes should be carried out by continuous and direct communication and interaction with all stakeholders, the NDP must be prepared in the neighbourhood and not by remote connection with the context. Hence, the NDO is the most proper agents to prepare NDP.

\subsubsection{Establishment in the Neighborhood}

As appointed before, NDP is provided by the direct, continuous, and constructive dialogue with all stakeholders; local community members, as the most important stakeholders, have unique position in the planning process. Hence, NDP is prepared by NDO with establishment in the neighbourhood and with the collaboration of experts in urban planning, architecture, economic, and social sciences fields. After the approval of the plan, the NDO monitors the executive steps and revises and upgrades the plan in regular periods.

\subsubsection{Recognition}

Every neighbourhood (as a socio-spatial organisation) has its unique social, economic, demographic, physical, structural, and environmental characteristics. One of the most important measures in providing a NDP is to distinguish each neighbourhood from others. Identifying the status quo of the neighbourhood in relation to each dimension (social, physical, etc.) and investigating tangible and intangible problems associated with that dimension is the first step of a NDP. An inclusive comprehension of the neighbourhood should be performed in this step. The following hints should be considered in identifying problems:

- recognition of the specific problems of the neighborhood;

- Prioritizing and determining the importance of each problem;

- Diagnosis and identification of key problems;

- Determining the casual relation between problems and their symptoms;

- Identifying locally programmable problems;

- Foresight possible problems generated by the implementation of the plan.

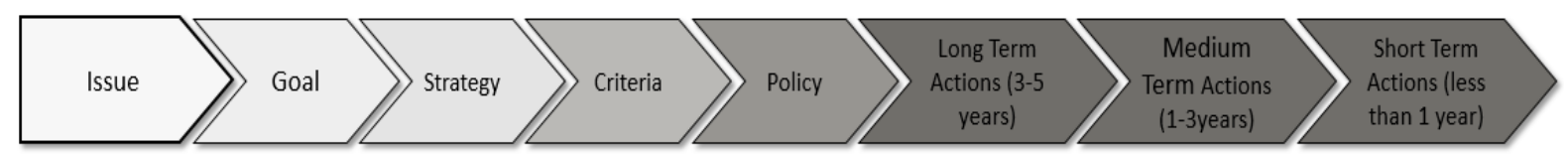

Figure 3. Different steps of NDP dynamic process, Source: (Developed by Authors). 
Beside the identification of problems, recognition is done to determine the capabilities of neighbourhood, and to communicate and analyse the opinions of the individuals, groups, and organizations that influence and are influenced by development. The most important stakeholders of NDP that should be identified and analysed are:

- District Municipality;

- Executive agencies and public service providers;

- Local community members;

- Local community organizations (such as CBOs or informal organizations that acting out at the neighborhood level);

- Trusted groups (such as councilors, neighborhood managers, trustees, and imams of mosques and religious delegations);

- Other executive bodies that (based on the certain characteristics or problems of the neighborhood) are effective in the development of the neighborhood.

\subsubsection{Communication}

In the next step, there is a need to connect with the local community; this connection has four aims:

- To identify and analyze local actors;

- To inform about the NDP and its goals;

- To obtain information and analyzing problems;

- To gain public trust and inclusive participation of the local community in the planning process.

Identifying the neighbourhood and finding the vital needs, problems, and demands of the residents can be proceeded by diverse methods; the information can be obtained from various resources in the municipality, executive bodies, or through survey of the local community and interaction with them (by questionnaires, interviews, $\mathrm{FGDs}^{7}$, and workshops). Basic information about the goals and benefits of NDP should be explained to persuade stakeholders and mobilise their participation. This transaction can be done by holding public meetings in public spaces or neighbourhood centres and organising interviews with various local community groups, local institutions, and trustees.

Properly interactive and transactive informing about the objectives of NDP will increase the awareness of citizens about the plan and, simultaneously, the local knowledge of planner about context. It must be considered that the rate and the quality of the participation of local community in planning process is directly related to the increase of awareness; also and on the other hand, increasing the awareness of residents enhances their analytical power and helps the planner to identify intervention priorities.

\subsubsection{Organizing participatory workshops}

As mentioned, status quo can be identified by numerous methods; however, participatory workshops have a distinct role. This method, by gaining inhabitants' trust, can institutionalise citizen participation at the neighbourhood

7 Focus Group Discussions level. Participatory workshops (whose members are made up of neighbourhood residents and organisations are involved in intervention process) can be effective in decision-making by summarising circumstances (both problems and capacities).

In these workshops, planner can obtain clearer and more reliable results through adjustments made about the importance and prioritisation of problems by members. So, holding participatory workshops to identify and prioritise local problems is the step of planning process that is organised after making communication with stakeholders. These workshops have different topics and members; they are continued until a consensus is observed.

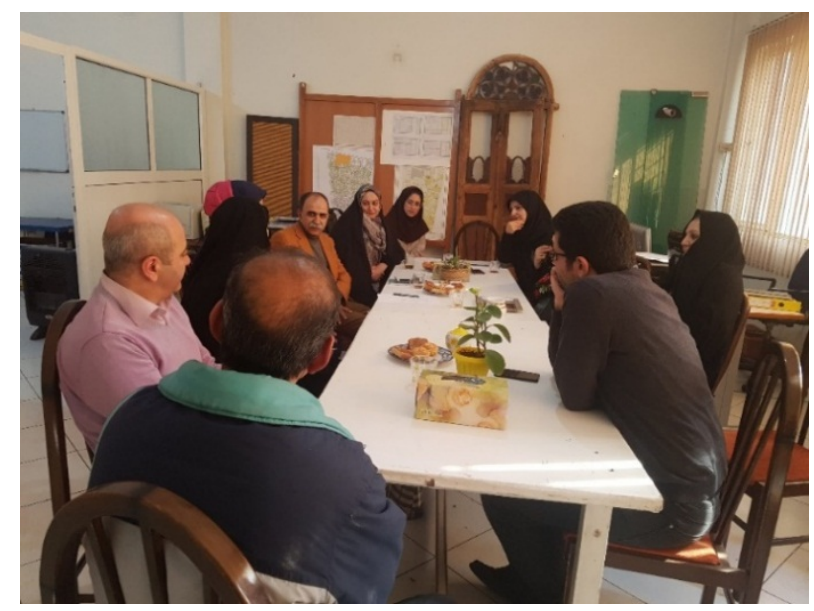

Figure 4. Example of participatory workshops held in neighbourhood

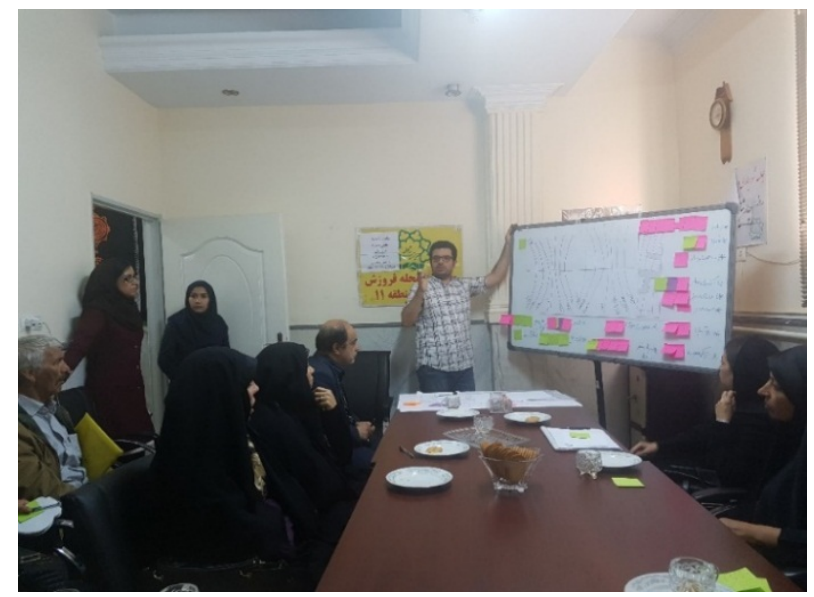

Figure 5. Example of participatory workshops held in neighbourhood

\subsubsection{Involvement of the community}

Activation of the capacity of local community to participate in NDP process needs to concurrent attention to individuals, groups, and community organisations. Involvement of community in planning process can be achieved by a combination of methods.

Creating or enabling community organisations is one of the useful methods. Local community organisations can act as representatives of residents; so, their opinion can be considered as the resultant of the view point of residents. In 
other words, these organisations can be imagined as the basis of hierarchical system of power distribution. In Tehran, although some individuals, groups, and local organisations have been formalised in the form of "Neighbourhood Aid-Councils", the authority of Aid-Councils and the reliance of inhabitants to them is limited and ambiguous. Therefore, in some cases, it is necessary to establish subject-oriented "community-based organisations (CBOs)" in accordance with the objectives of NDP. It must be considered that creating, training, enabling, and strengthening a $\mathrm{CBO}$ is a time-consuming process, and the steps of gathering members, consolidating them, and the legal process of registering should be done gradually.

Also, interaction and consultation with public organisations has a vital role. The solutions and problem-solving steps, which are proceeded with the collaboration of local community, must be presented to the public sector agencies, because -in the most cases- they (such as municipality, infrastructure and public service providers, and supportive institutions) have the exclusive authority to solve the problems of the neighbourhood; hence, representatives of the public bodies at the neighbourhood level should be informed about the local problems in this step.

\subsubsection{Participatory deployment of an action plan}

By identifying and prioritising problems and capacities through involved community and institutions the next step is to configure a NDP. The NDP prescribes an effective framework to casual and high-priority problems and gives reasonable and realisable solutions to the problems.

The individuals, groups, and organisations that have helped planner to recognise and prioritise problems can suggest their solutions through the same technique; also, organising participatory workshops in the deployment stage can lead to their participation in the implementation and monitoring processes.

To figure out an action plan, first of all, a collective vision must be imagined for the neighbourhood. The most important role of the planner is to navigate stakeholders to a consensus on drawn vision.

In the next step, goals, objectives, policies, and strategies are proposed with the navigation of the planner. In participatory workshops that are held to set goals, etc., the planner, taking into account the problems prioritised in the previous stage, should ask the local community for their proposals; in this step, the planner's role -as a navigatorwill be more prominent because the deviation of proposed goals from addressing high-priority problems will doubt the plan from expected outcomes.

\subsubsection{Defining, prioritizing, and levelling up actions}

Executive actions of NDP (resulted from goals, strategies, etc.) are defined as the output of the plan. These actions are grouped in three levels:
- Short-term actions refer to the activities that are -in the most times- urgent and must be completed within a maximum of one year. Various actions to improve the social and environmental quality of neighborhood are in this field. Such actions, due to rapid implementation, have positive effect on gaining and improvement of public trust. Public participation in such actions can be activated by using techniques such as "participatory budgeting, financing, and implementation” (simultaneously by community and public sector);

- Mid-term projects refer to the projects that take 1 to 3 years to implement and complete. Small-scale projects can be put into this category. Creating open/green spaces or modification and rehabilitation of streets and alleys are samples of mid-term projects;

- Long-term programs are those take more than 3 years to complete (almost 3 to 5 years). The reason of time-consuming of these programs is the scale and cost of their implementation. Most of them are about provision of amenities, public service, and infrastructure, reorganization of paths, and renovation and reconstruction of houses.

\subsubsection{Adaptation with meso/macro plans}

Compliance with the other plans (such as district's detailed and executive plans, city's comprehensive and strategic plans, and public bodies' sectorial plans) is a consideration that can increase the feasibility of NDP. This cohesion is made by paying attention to the regulations and limitations of the parallel and upstream plans. But, at the same time, if the NDP has adjustable proposals which conflicts with other plans, it must predict necessary measures to update or revise them.

\subsubsection{Upgrade and revise of NDP}

Flexibility should be considered in determining the all parts of NDP (from vision to action), because the neighbourhood (as a socio-spatial organisation) and the local circumstances change continuously over time, and the needs and demands of the neighbourhood also change with the implementation of some projects. So, providing flexible plans that can adapt themselves with dynamic context is a vital consideration.

\subsection{Mechanism of the Implementation of NDP}

After preparation, the NDP, is presented to the municipality and other responsible agencies for checking, modification, and approval. Then it is discussed at "Urban Regeneration Council of the District" and finally, it is endorsed in the "Urban Regeneration Council of Tehran"; after final approval, the NDP is turned into collective commitment of all stakeholders.

In the implementation phase, similar to planning process, individuals, groups, and community organizations should 
be activated. In this step, stakeholders are informed about the details of implementation, prepared budgets, executive bodies, and executive, financial, and legal limitations. Participation of local communities in implementation stage can raise their self-commitment about the NDP. Executive procedures can be different based on the priority and level of every measure.

Short-term actions can be outsourced to the contractors; but, as appointed before, due to the small scale and the low cost of implementation, financial and executive participation of community is a more optimized way for the realization of such actions.

Mid-term projects and long-term programmes need more time and budget; usually, the necessary budget for these projects is provided by public sector (the municipality or other public bodies). The most important consideration of these projects is to implement and realise them in predicted period, because they have a vital effect on the liveability of the neighbourhood.

\subsection{Monitoring NDP}

Ambiguity of monitoring is a serious obstacle in realisation of NDP; it means the lack of a systematic assessment of implementation process and achieved goals and objectives. Moreover, monitoring helps to identify NDP's weaknesses and provide useful information for stakeholders in future reviews. Continuous monitoring, evaluation, and review of the implementation process of the NDP is an important part of planning that must be happened every year.

The items that should be considered in the monitoring of NDP are:

- Compliance of the implementation with the NDP and control of possible deviations;

- equilibrium in implementation and promotion of actions in all dimensions;

- Assessment of the social impact of each project during implementation;

- Monitoring the allocated and spent budget;

- Control of the quality of implementation and the degree of stakeholders' participation in the implementation process;

- Adherence to the schedule set for the projects' implementation.

Monitoring NDP and creating necessary coordination between numerous authorities are the responsibilities of "Urban Regeneration Council of the District"; this duty, due to the establishment of the NDO in neighbourhood, can be delivered to this institution.

Figure 5 shows the content of the NDP at aspect and criterion levels; these metrics must be analysed in recognition and implementation stages and, also, at the end of period of plan; the evaluation of implementation can define the effectiveness of NDP.

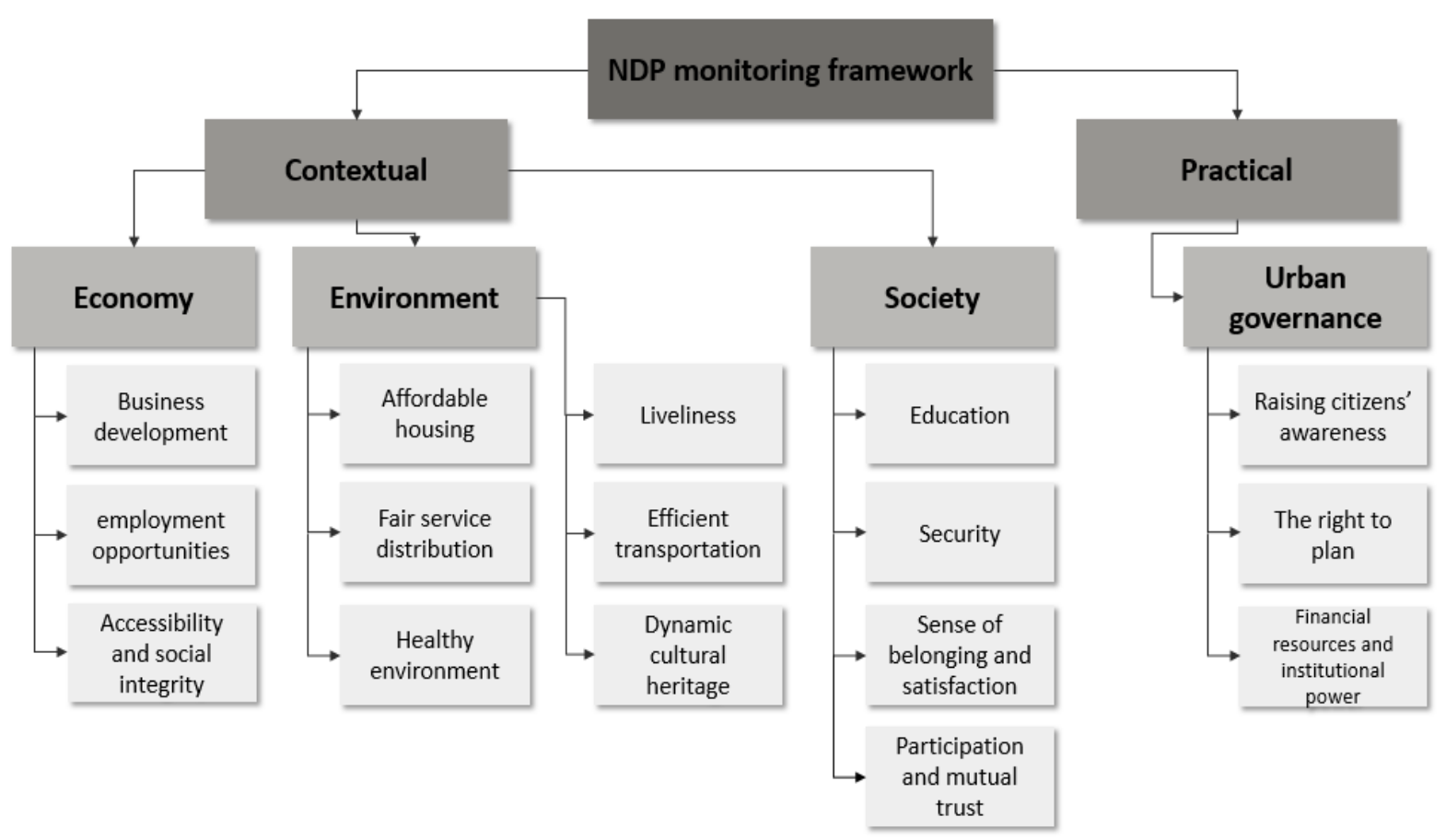

Figure 5. NDP monitoring framework, Source: (Developed by Authors). 


\section{Conclusion}

Various approaches and measures have been adopted in Tehran for the regeneration and renewal of deteriorated neighbourhoods in different eras; most of them were aimed at solving the problem in a one-dimensional way. The most important weak spots of previous approaches were the lack of equilibrium, shortage of integration, marginal position of inclusiveness, and absence of assessment of the efficiency and effectiveness of plans. Two decades ago, after preparing top-down and authoritative plans in Tehran, centralised implementation of these plans, and facing negative consequences of intervention, the urban strategy of neighbourhood-orientation in the renewal of deteriorated neighbourhoods entered the practice of Tehran Municipality and its executive organisations; by considering problem-solving and participation, NDP can be considered as the main outcome output of this paradigm shift, which for sure is not the end point.

In this paper, the need to a paradigm shift in planning for deteriorated neighbourhoods is concluded from the assessment of previous plans and proved the necessity for an approach with concentration on problem-oriented and partnership-oriented axes simultaneously. This approach must put necessary action in different priorities and levels and ensures the participation and collaboration of all stakeholders in all stages. The new paradigm is about planning for a neighbourhood by establishment in it, with the maximum participation of the local community, and the collaboration of other stakeholders in a cyclic process.

\section{Conflict of Interests}

The Authors report the following details of affiliation or involvement in Urban Renewal Organisation of Tehran (UROT):

- Employment or voluntary involvement

- Involvement in legal action related to the work.

\section{REFERENCES}

[1] Word Bank, Urban Development Plan, WordBank, 2018.

[2] P. Taylor, "UNCHS (Habitat) - the global campaign for good urban governance", Environment\&Urbanization, vol. 12, no. 1, pp. 197-202, April 2000.

[3] C. Eken, "Learning from Resilience: Cities towards a Self Organizing System," Journal Of Contemporary Urban Affairs, vol. 3, no. 1, pp. 92-103, 2019. DOI: 10.25034/ijcua.2018.4686

[4] J. A. Adedeji and O. Arayela, "Urban Renewal Strategies and Economic Growth in Ondo State, Nigeria: A Case Study," Journal Of Contemporary Urban Affairs, vol. 2, no. 1, pp. 76-83, 2018.
[5] R. Biswas, A. Jana, K. Arya and K. Ramamritham, "A good-governance framework for urban management," Journal of Urban Management, vol. 8, no. 2, pp. 225-236, 2019. DOI: 10.1016/j.jum.2018.12.009

[6] N. F. d. Cruz, P. Rode and M. McQuarrie, "New urban governance: A review of current themes and future priorities," JOURNAL OF URBAN AFFAIRS, vol. 41, no. 1, pp. 1-19, 2019. DOI: 10.1080/07352166.2018.1499416

[7] L. Beattie and E. Haarhoff, "Urban Growth, Liveability and Quality Urban Design: Questions about the efficacy of urban planning systems in Auckland, New Zealand," Journal of Contemporary Urban Affairs, pp. 12-23, 2018. DOI: 10.25034/ijcua.2018.3667

[8] A. Sharifi, " From Garden City to Eco-urbanism: The quest for sustainable neighborhood development," Sustainable Cities and Society 20, pp. 1-16, 2016. DOI: 10.1016/j.scs.2015.09.002

[9] J. McCarthy, Partnership, Collaborative Planning and Urban Regeneration, London: Routledge, 2007.

[10] H. Ahmad Nia and y. H. Suleiman, "Identity in Changing Context: Factors of losing Identity in new developed part of the city of Famagusta, North Cyprus," Journal of Contemporary Urban Affairs, vol. 1, no. 2, pp. 11-20, 2017. DOI: 10.25034/ijcua.2017.3644

[11] F. Wassenberg and K. v. Dijken, A practitioner's view on neighbourhood, Hague: Nicis Instotite, 2011

[12] E. Haselsteiner, B. V. Rizvanolli, P. V. Sáez and O. Kontovourkis, "Drivers and Barriers Leading to a Successful Paradigm Shift toward Regenerative Neighborhoods," Sustainability 13, pp. 1-22, 2021. DOI: 10.3390/su13095179

[13] Q. Zhang, E. H. K. Yung and E. H. Wan Chan, "Towards Sustainable Neighborhoods: Challenges and Opportunities for Neighborhood Planning in Transitional Urban China," sustainability 10,406, pp. 1-23, 2018. DOI: 10.3390/su10020406

[14] B. Holmes, "Citizens' engagement in policymaking and the design of public services," Parliament of Australia , Australia , 2011.

[15] M. Alam and E. Upoma Baidya, "Empowering the Urban Poor through Participatory Planning Process: A Case from Jhenaidah, Bangladesh," Journal Of Contemporary Urban Affairs, vol. 3, no. 2, pp. 47-54, 2019. DOI: 10.25034/ijcua.2018.4700

[16] City of Joondalup, "Community Development Plan," Joondalup, 2020.

[17] T. S. Haksever and C. Çinar Çitak, "The Coordination of Actors in Urban Regeneration Projects: Fikirtepe, Istanbul, Turkey," Journal Of Contemporary Urban Affairs, vol. 3, no. 2, 2019. DOI: $10.25034 /$ ijcua.2018.4708

[18] B. Khakpur, E. Mafi and A. Bavan poori, "Social wealth role in neighborhood sudtainable development," Geography and regional development 12, pp. 50-62, 2009.

[19] A. Andalib, A. khani, M. Karimi and H. Mashayekhi, Emerging deteriorated urban areas of Tehran city, Tehran: Azarakhsh, 2018.

[20] K. Hajialiakbari and A. Shafeei, Neighborhood 
Development, A framework for dysfunctional neighborhoods, Tehran: Tehran Urban Planning and Research Center, 2018.

[21] UROT, Tehran Flag Projects, Tehran: Shahr Publication, 2015.

[22] M. Habibi and M. Maghsoudi, Urban Renewal, Tehran: University of Tehran, 2005.

[23] A. Mansouri and A. Khani, Specialized Renewal plan for deteriorated area in Tehran, Tehran: Reypour, 2007.

[24] The Parliment Research Center, "Sixth Economic, Social, and Cultural five-year Plan of the Islamc Republic of Iran," The Parliment Research Center, Tehran, 2017.

[25] The Parliment research Center, "National Strategic Plan of Urban Regeneration," The Parliment research Center, Tehran, 2015.
[26] UROT, "The Official Framework of the Urban Regeneration Council of Tehran," UROT, Tehran, 2015.

[27] Islamic City Council of Tehran, "The 3rd five-year Development Plan of Tehran," Islamic City Council of Tehran, Tehran, 2018.

[28] S.-K. Lai, "Why plans matter for cities," cities, vol. 73, pp. 91-95, 2018. DOI: 10.1016/j.cities.2017.10.014

[29] K. Hajialiakbari, "The Rise of the Facilitation Approach in Tackling Neighbourhood Decline in Tehran," in Urban Heritage Along the Silk Roads; A Contemporary Reading of Urban Transformation of Historic Cities in the Middle East and Beyond, London, Springer, 2020, pp. 55-74.

[30] A. Andalib and K. Hajialiakbari, "An identification of the neighbourhood renewal process in Tehran: Case study Khoob-Bakht neighbourhood, Tehran, Iran," Journal of Urban Regeneration \& Renewal, 2019. 